Journal of Computer Science 4 (12): 1064-1070, 2008

ISSN 1549-3636

(C) 2008 Science Publications

\title{
Life Long Learning: Seniors in Second Life Continuum
}

\author{
${ }^{1}$ Cheryl D. Seals, ${ }^{1}$ Wanda Moses, ${ }^{1}$ Justus Nyagwencha, ${ }^{1}$ Aqueasha Martin, \\ ${ }^{1}$ Kelley Clanton, ${ }^{2}$ Chippewa M. Thomas and ${ }^{3}$ Felicia Doswell \\ ${ }^{1}$ Department of Computer Science and Software Engineering, Shelby Center for Engineering Technology, \\ Suite 3101, Auburn University, Auburn, AL 36849-5347, USA \\ ${ }^{2}$ Department of Special Education, Rehabilitation, Counseling/School Psychology, \\ Auburn University, Auburn, AL 36849-5222, USA \\ ${ }^{3}$ Department of Computer Science, Norfolk State University, Norfolk, VA 23504, USA
}

\begin{abstract}
Senior citizens represented the fastest growing demographic worldwide. As indicated in the Year 2000 US Census, there were 35 million people 65 or older in the US and by 2030, it was estimated that there were about 70 million older adults in the US alone. With the older population growing rapidly and being increasingly exposed to computers and technology, it is important that they are aware of what computers can do for them (e.g., Email, document creation, games, Internet and educational training). This study was conducted to identify best practices for designing and creating applications for a senior population while also promoting computer and Internet use among seniors. The longitudinal study employed a mixed method approach to data collection and analysis and included the use of standardized surveys, measures of physical fitness and physiology, observations in their retirement community and interviews. Auburn University faculty in the College of Engineering engaged senior citizens to participate in workshops designed to develop their skills in computing. Results of the study indicated virtual classrooms in SecondLife as a viable tool for senior adult education. The potential significance of this project was to create a valid, reliable and reproducible model for outreach to retirement communities and senior activity centers.
\end{abstract}

Key words: Adult learning, senior citizens, SecondLife ${ }^{\circledR}$, virtual world, online communities

\section{INTRODUCTION}

According to the United States Census Bureau, the growth of the senior (65 years+) and pre-senior (5464 years) population has and will continue to see upward trend in the years to come. People are living longer healthier lives. However, this is not the same trend among Internet users. Seniors as Internet users are underrepresented. It has been found that seniors are less likely to make use of the Internet than any other user group $^{[4]}$. The Internet provides a wide array of resources and tools that can be beneficial to senior populations.

Progress has been made in tackling design issues that limit or discourage seniors from participating as Internet users. Based on these studies, progress has been made. Seniors appreciate social interaction, affiliation and support as a few among many attributes that encourage Internet use ${ }^{[4]}$. Guidelines issued by the NIA/NLM for designing senior friendly websites are widely available. However, a study of over
125 websites reveals that many online web pages do not follow these guidelines for their designs ${ }^{[3]}$.

The goal of this study was to identify best practices for designing for a senior population while also promoting computer and Internet use among seniors. Based on survey data collected through initial research with the client, topics of interests were identified and three of these were chosen as themes for classroom design. The requirements for the project were to create virtual classrooms in SecondLife that were of interest to seniors, produce a supporting website for the project and to create a tutorial to explain how to use the classrooms. Through this study, we evaluated the process of designing for seniors in a virtual world.

Literature review and background: Virtual worlds can be used for many real world activities ranging from socializing, trade, hangouts, sports arenas, marketing zones, academic facilities as well as battle fields with the use of avatars to referent humans. In the academic world, faculty use virtual worlds for learning activities, where

Corresponding Author: Cheryl D. Seals, Department of Computer Science and Software Engineering,

Shelby Center for Engineering Technology, Suite 3101, Auburn University, Auburn, AL 36849-5347, USA

1064 


\section{J. Computer Sci., 4 (12): 1064-1070, 2008}

students apply, analyze and problem-solve using course content and ideas. This can include the following:

- Role-play

- Operating simulated equipment

- Designing and building things such as houses, bridges, clothing, jewelry, businesses, newspapers.

- Interacting with instructor-built or creating studentbuilt simulations of physical or procedural processes $^{[2]}$

There are a growing number of educators joining SecondLife who are interested in teaching in SecondLife. Although educator's subscriptions seem to be an upward trend, it is yet to be known whether teaching in SecondLife is an effective teaching tool.

SecondLife: SecondLife (SL) was developed by Linden Research Inc., as an Internet-based virtual reality environment launched in June 23, 2003. It has gained international acclaim through media outlets due to its use for emulating virtually anything in real life. SecondLife has Residents who are represented as avatars who can interact with each other through the SecondLife Viewer, which provides a social network service combined with general aspects of meta-verse. Residents can explore, meet other residents, socialize, participate in individual and group activities and create and trade items (virtual property) and services with one another ${ }^{[12]}$. SecondLife has been adopted as a platform for education activities by many institutions, such as colleges, universities, libraries and government entities that have fully ascribed to it. There are over a hundred regions/examples where SL is used for educational purposes covering subjects such as computer science, engineering, chemistry, art and even communication through e-mail. Instructors and researchers in SecondLife are in favor of it rather than traditional distance learning because it is more practical. Over $80 \%$ of the British research universities and significant number of US universities have found the benefit of utilizing SecondLife for the development and delivery of distance education. They have found that development, teaching and/or learning activities, which use SecondLife; can be used to increase credit units offered to students interested in distance educations and alternative to traditional classroom education ${ }^{[12]}$.

SecondLife's usefulness as an education tool is significant in learning institutions but has been underutilized as a learning tool for the senior population (i.e., America's fastest growing population). This study was to introduce seniors to SecondLife as an exercise in participatory design. We gathered requirements to better support the creation of an educational platform to support seniors.
The senior community is unique in that they have a much different agenda than typical users. We have provided workshops in the past where their interest were not peaked, leaving the facilitator puzzling over which types of applications are of interest or beneficial to seniors. To create interesting future workshops and supportive applications, data was collected from AU seniors with questionnaires to ascertain their areas of interest as shown by the statistics on the data analysis section. Three of the most important areas, health, art and e-mail, were chosen and implemented as classes in SL and tested for its usability with the AU seniors.

\section{MATERIALS AND METHODS}

The study was conducted for eight-weeks. In preliminary research conducted by the client, surveys were administered to gauge the interests of a senior group. Based on this survey data, three of the most requested themes were chosen for classroom design. $\mathrm{Bi}$ weekly meetings scheduled with the client to discuss design ideas including the requirements, wireframe, conceptual model and final design of the classroom.

Participatory design with seniors: Surveys from approximately 35 senior citizens were evaluated to determine what areas were of most interest to them. There was a wide variety of items listed including interests such as gardening, reading, health, swimming and the civil war (Fig. 1). After tallying the results, three areas were selected from among the top seven topics to use for designing classes for the AU Computing Seniors in SecondLife. The top seven topics included reading, internet, gardening, art exhibits, art history, email and health care (Fig. 1).

Approach: Our approach was to develop environment that felt comfortable and were usable to senior citizens to reduce their cyber phobia and put them at ease in a new environment. We gathered requirements, designed and developed an environment that would be comfortable for our audience. We then planned for our population to interact in a series of workshops to test whether seniors were benefited from this type of virtual education experience.

We implemented virtual classrooms to introduce Art exhibits, email instruction and connections to health care information. From the date gathered most of our senior participants, as with most from their generation selected reading as their most popular pastime and the most familiar activity. They chose this overwhelmingly, but our rationale to develop for other types of instruction was based on teaching something new that they would find a great interest in and our ability to provide these as lessons as a virtual classroom activity. 


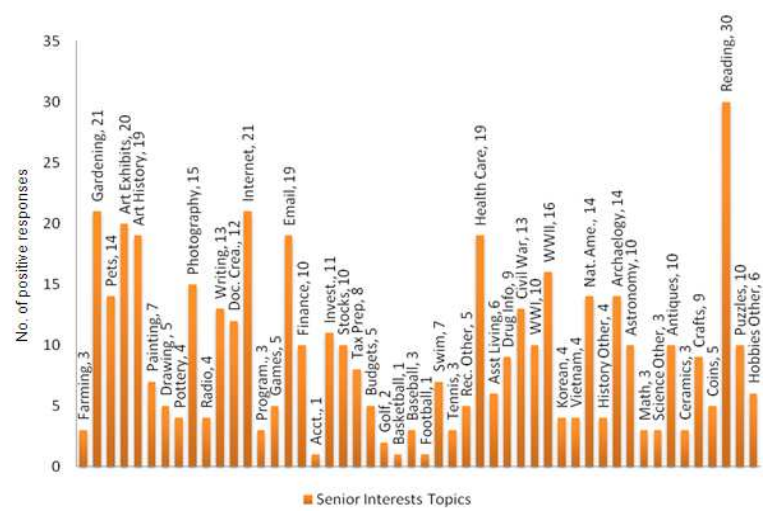

Fig. 1: Results of senior interest from survey

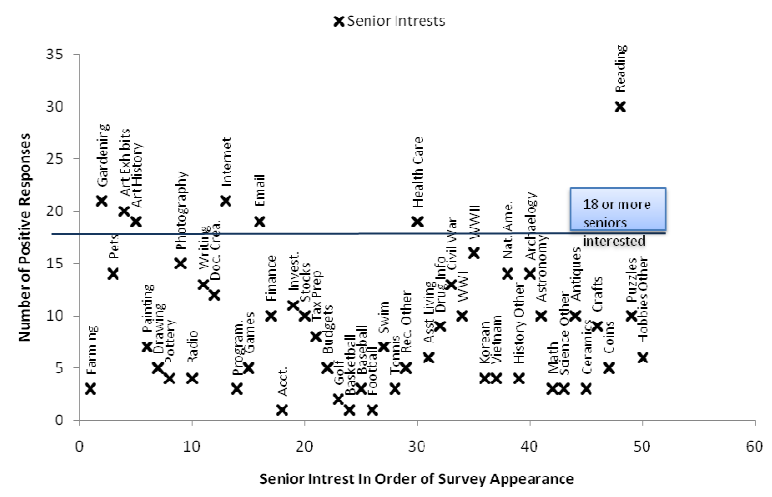

Fig. 2: Results of senior interests from survey

Our hope was that these virtual classrooms would be an interactive and social attempt to get seniors more excited about new technology and reduced their cyber phobia. Each designer choose a topic based on his or her interest and familiarity with the content material.

Figure 2 shows the explicit threshold for selecting Areas to develop for this initial set of curriculum development. We also considered that some senior citizens may not be familiar with using computers since the technological age did not come about until they were well into middle age. Therefore preparing classes that are computer-based may require instructions with many details to support novice computer users. The detailed nature of senior workshops was to support seniors and encourage even those with little computer experience.

The comfort level of senior citizens in a traditional classroom was also taken into consideration. Day-time and weekday hours may not be convenient for older adults who have jobs and families to care for. Thus the idea of online classes designed in SecondLife that can be accessed in the comfort of their own homes, at a center for senior citizens, a church, in an RV while traveling, morning, noon or night provides for a more flexible learning experience.

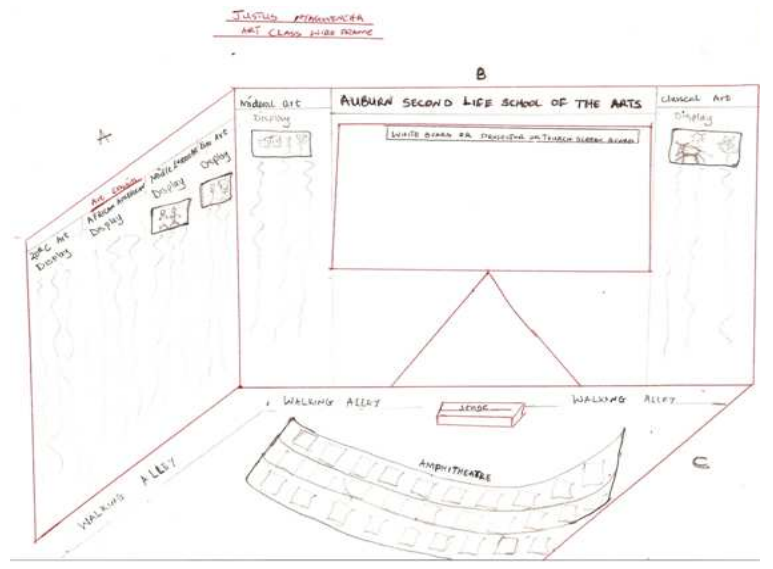

Fig. 3: A high-level wireframe of the planned design of the art classroom in SecondLife

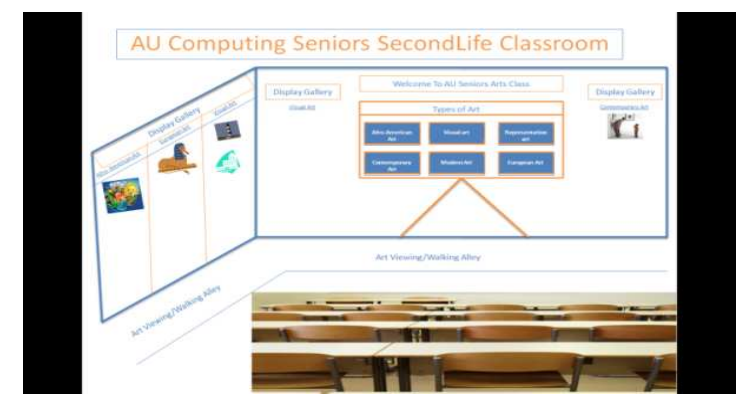

Fig. 4: A more detailed conceptual model of the planned design for the art classroom in SecondLife

Wireframe and conceptual model: Each designer completed a wireframe and conceptual model of the classroom they designed (Fig. 3 and 4). These deliverables were presented to the client and modified according to the client's specifications. The conceptual model included a paper prototype and task scenario of each classroom. Additionally, hardware and software requirements for SecondLife were listed and a lexicon of common terminology was prepared and presented to the client for approval.

AU art classroom: The AU Art classroom was designed to expose seniors to different kinds of art (Fig. 5). The class will provide general information on different types of art including visual art, AfricanAmerican art, representation art, contemporary art, modern art and European art. At the foremost, users are required to read/view the introduction part on the art class to learn more about au-seniors in SecondLife before proceeding further. However, returning users were encouraged to select subject of interest within the art classroom from the tutorial display boards and proceed with learning. 


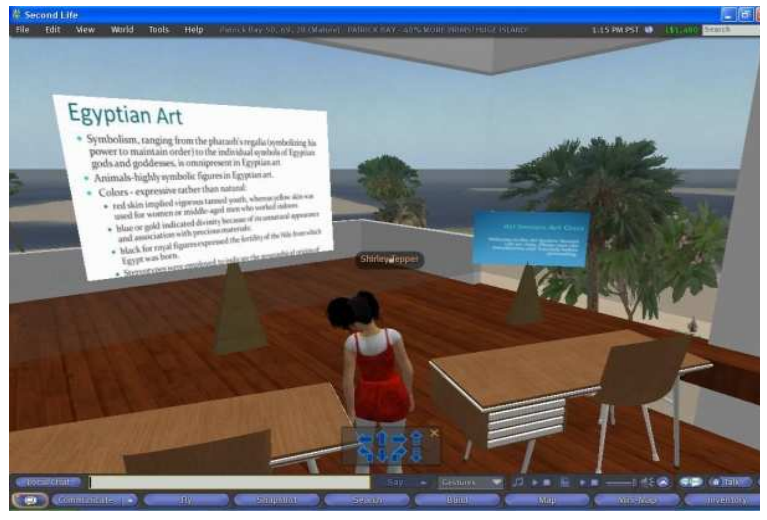

Fig. 5: The final implementation of the art classroom in SecondLife

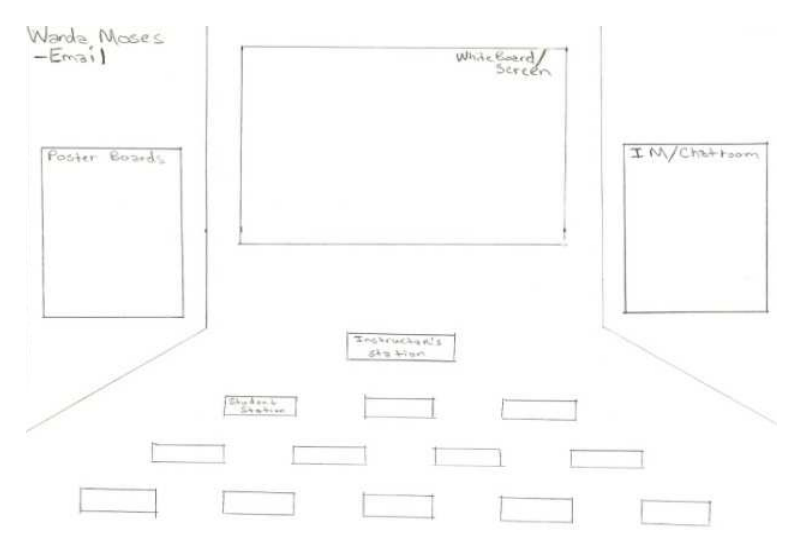

Fig. 6: A high-level wireframe of the planned design of the email classroom in SecondLife

If the user chooses the virtual art classroom, through the button on the main menu, they will be linked to the art class within the SecondLife Education Island. Users may need to create accounts in SecondLife to be able to carry out the necessary actions within the island. Once in the classroom, users through their avatars can teleport to all parts of the classroom. As beginners, users can either sit or start an art presentation or they can walk along the isle and study/view different types of art facts. Before any tour, seniors should watch an introductory presentation on different types of arts. With this type of instruction, seniors choose art of interest and teleport to the location to view or study the art. The classroom presentation may be expanded to include minipresentation on various every specific art types respectively. At the end of the class, seniors make their comments and if they wish, suggest changes to improve on the class. Users then complete a survey on the usability issues associated with the class design, logout or teleport to another class.

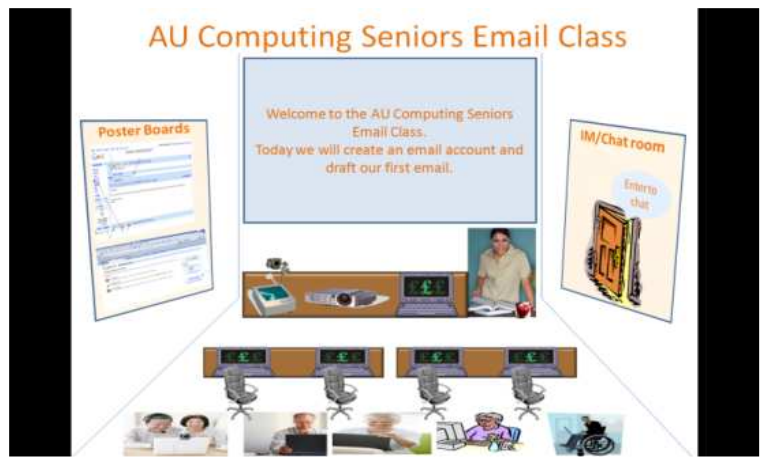

Fig. 7: A more detailed conceptual model of the planned design for the email classroom in SecondLife

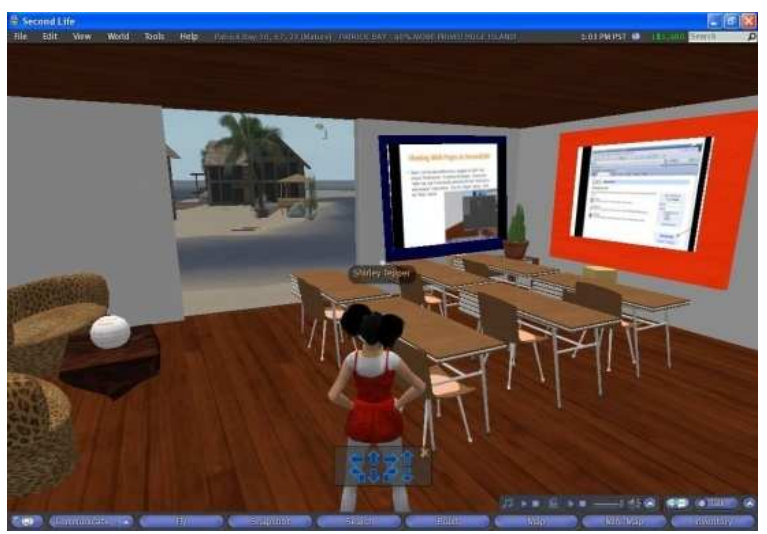

Fig. 8: The final implementation of the email classroom in SecondLife

AU Email classroom: The AU Email classroom was designed to teach seniors to setup and use an Email account (Fig. 6-8). The class provides a tutorial on creating an Email account using Gmail and sending an Email to a recipient.

In the Email classroom, the seniors enter and take a seat at a computer station, turn on the computer, log into their individual accounts and follow along as the instructor walks through the process of preparing and sending emails. The instructor conducts the class by projecting the image of her computer monitor's screen to the whiteboard at the front of the class so that everyone can see what she is doing.

Step 1: Create an email account. If the student has an Email account, he or she can proceed to Step 2. If not, the student will use Google's Gmail to create an account. The student follows the direction:

- Open a web browser

- Navigate to Google's web site by typing www.google.com into the web browser address box 
- Click on the "Sign up for Gmail" link located at the bottom right hand side of the web page

- Complete the information on this page, then click the "I accept. Create my account." button at the bottom of the page. The next page is an introduction to Gmail

- Click the link at the bottom of the page to sign into the Gmail account

Step 2: Compose an Email:

- Click on the "Compose Mail" link located at the upper left hand corner of the web page. The cursor is now in the "To" box of the new email

- Enter the email address of the recipient. An example is: username@gmail.com

- Click the tab button and move to the subject box and type in the subject

- Click the tab button and move to the message body to type the message. When you have completed your message, click on the "Send" button at the bottom of the page and the message will be sent

- A copy of the message will also be placed in the "Sent Mail" folder located on the left hand side of the web page

- To save a draft and send the message at a later time, click on the "Save now" button and the message will be saved in the "Drafts" folder located on the left hand side of the web page

- To "Discard" the message and not send, click on the "Discard" button and the message will be deleted

Step 3: Attach a picture to an Email:

- Click on the "Attach a file" link located under the subject line. This will take you to your file folders

- Search for the picture you would like to add to your email. Double click on it or click on it once then click on open. The file name will appear next to the paperclip under the subject line

- You will have the option to remove the file, otherwise continue to type your message, add another picture or send your message

\section{RESULTS AND DISCUSSION}

AU virtual health fair: The AU Virtual Health Fair was designed to provide seniors with information about searching for health and health-related topics on the Internet (Fig. 9-11). The health fair provides a short introduction to performing a search using Google for health information. The classroom also provides links to resources supporting healthy living available on the web and in SecondLife.

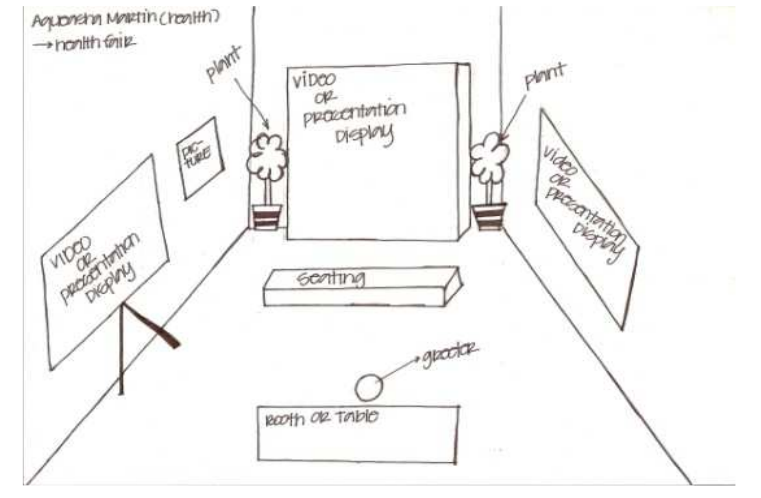

Fig. 9: A high-level wireframe of the planned design of the virtual health fair classroom in SecondLife

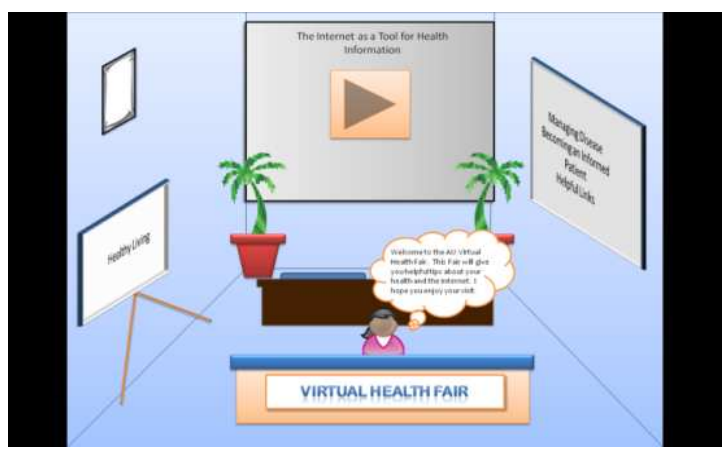

Fig. 10: A more detailed conceptual model of the planned design for the virtual health fair classroom in SecondLife

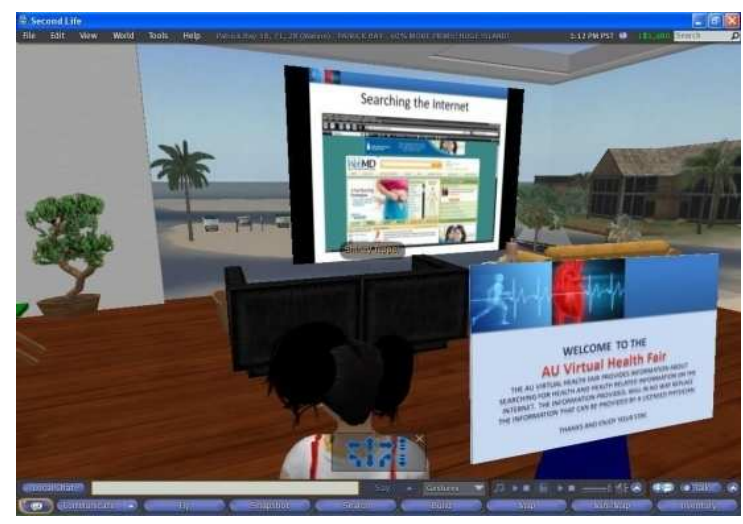

Fig. 11: The final implementation of the virtual health fair classroom in SecondLife

If a user wishes to visit the AU Virtual Health fair to learn more about finding health information online, he or she must teleport to Prize Island. Upon entering the AU Virtual Health Fair classroom a user receives a disclaimer stating, "The AU Virtual Health Fair provides tips about finding Health Information using the Internet. 


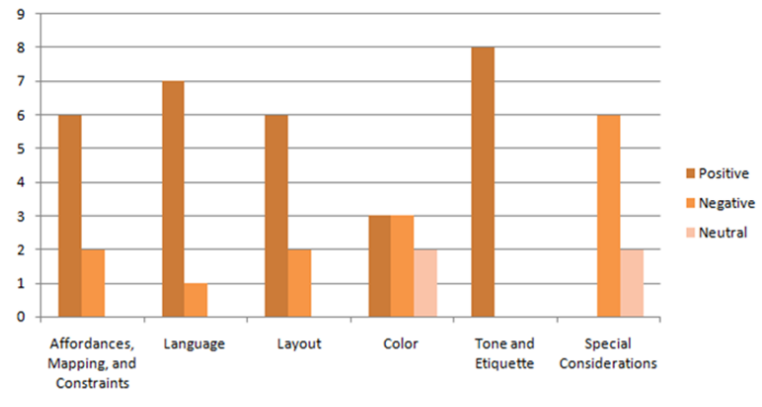

Fig. 12: Results of heuristic evaluation

The AU Virtual Health Fair in no way will attempt to diagnose any disease and in no way replaces the advice that is provided by a licensed physician." After viewing the disclaimer, a user is presented with three choices (1) Healthy Living (2) The Internet as a Tool for Health Information and (3) Managing Disease, Becoming an Informed Patient and Helpful Links.

If a user chooses to learn more about Healthy Living, after touching the Healthy Living board he or she is presented with several links to websites promoting healthy living through diet and exercise. A user then decides to learn more about "The Internet as a tool for Health Information". This presentation provides a short introduction to searching the Internet using Google and presents important terms such as browser, keywords and URL. After completing the short tutorial, a user then decides he or she wants to use this information to learn more about managing disease, becoming an informed patient and visiting helpful links. $\mathrm{He}$ or she is then presented with links that point to information on each of the various topics.

Evaluation and analysis: Upon the completion of the design phase, a set of usability evaluations were conducted. These evaluations included a heuristic evaluation and a usability test. From the heuristic evaluations it was determined that the general design of the system exhibited good design principles. The heuristics focused on the following characteristics: affordances, mappings, constraints, language, layout, color, tone and etiquette and special considerations. The results of the heuristic evaluation are shown in Fig. 12. Changes were made to the system's layout based on these results.

The usability study included 6 participants. Each participant was given a pre-questionnaire to determine their familiarity with computers. Based on the results of the pre-questionnaire participants had an average of 12 years of computer experience and $100 \%$ of the participants had taken a computer related class. Of the participants, $100 \%$ were comfortable using software applications such as email clients, instant messengers and web browsers.

Each participant was then given the following task list based on the functional requirements:

Task list-Emails: Using the resources in the SecondLife AU Email classroom:

- Create an account in Google's Gmail

- Compose an email and save it as a draft

- Compose an email and send it to auseniors@auburn.edu

- Attach a picture to an email

Task list-Virtual health fair: Using the resources in the SecondLife AU Health classroom:

- Search for information about diabetes

- Search for information on breast cancer

- Search for information on exercising or find a recipe

- Search the Internet and find information about Medicaid or Medicare

Task list-virtual art: Using the resources in the SecondLife AU Art classroom:

- Click on the whiteboard to view the introduction

- View Modern art

- View Egyptian art

- View Afro American art

After completing the task list each participant was asked to complete a post-questionnaire to determine the usability of the system. We found some very promising results of utilizing SecondLife for virtual education. Based on the results from the post-questionnaire it was determined that nearly $84 \%$ of the participants found navigating the classes to be easy. Also another area that were highly ranked was "The system will be fun for sending an email was $66 \%$. Three other areas were also highly ranked with $33 \%$ of users strongly agreeing with the usability of these areas which are the following: "system easy to get started"; "good understanding of how to use this system to create an email account"; and "the use of the virtual work was easy". One area was also highly ranked with $33 \%$ of users agreeing to the positive usability of this activity: "The system will be easy to use by people who don't know much about computers". Some of our other results indicated that we need to improve or simplify tool and command location. For a complete listing of all results of the usability test see Fig. 13. 


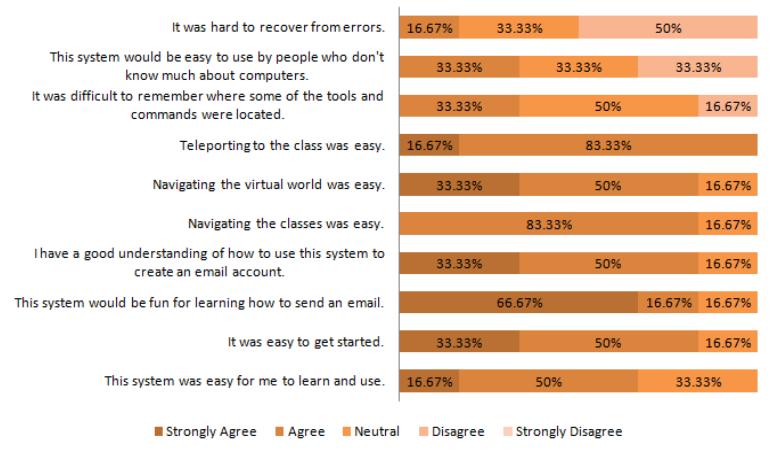

Fig. 13: Results of usability test

\section{CONCLUSION}

Based on the results of the usability study, it was found that designing a virtual classroom in SecondLife is a viable tool for education in the senior population. SecondLife provides a fun learning environment that is accessible to a large population. The applications and tutorials we created in the SecondLife virtual environment supported participants in accessing information conveniently and from the privacy of a preferred location. This provides an advantage over traditional classroom settings which are usually more structured in terms of time and location. However, more research is required to determine if this approach will be effective in promoting learning activities and increasing interests in using virtual worlds for educational and academic purposes.

With the older population growing rapidly and being increasingly exposed to computers and technology, it is important that they are aware of what computers can do for them (e.g., Email, document creation, games, Internet and educational training). With this SecondLife Virtual Classroom experience, we increased seniors knowledge of computer applications and promoted their future use of computer technology.

We identified areas of interest for seniors and utilized that to create a learning environment that would support seniors and promote computer interest and computer literacy. This is a longitudinal study and we will take the information from this preliminary study to help refine this virtual classroom for increased usability and wider appeal in the senior citizen community. Our results indicated that their were many areas where they were highly pleased and comfortable to be interacting in virtual classrooms in SecondLife The potential significance of this project is to create a valid, reliable and reproducible model for outreach to retirement communities and senior activity centers. We feel that this workshop was a very good exploratory step to support this direction of research.

\section{REFERENCES}

1. Antonacci, D., S. DiBartolo, N. Edwards, K. Fritch, B. McMullen and R. Murch-Shafer, 2008. A SecondLife Primer and Resource for Exploring the Potential of Virtual Worlds to Impact Teaching and Learning White Paper July 2008. http://www.angellearning.com/products/secondlife/ downloads/The Power of Virtual Worlds in Education_0708.pdf

2. Armac, I. and D. Retkowitz, 2007. Simulation of smart environments. Proceedings IEEE International Conference on Pervasive Services, July 15-20, IEEE Xplore Press, Istanbul, pp: 257-266. DOI: 10.1109/PERSER.2007.4283924

3. Becker, S.A., 2004. A study of web usability for older adults seeking online health resources. ACM Trans. Comput. Hum. Interact. 11: 387-406. http://doi.acm.org/10.1145/1035575.1035578

4. Ito, M., V.L. O'Day, A. Adler, C. Linde and E.D. Mynatt, 2001. Making a place for seniors on the Net: SeniorNet, senior identity and the digital divide. SIGCAS Comput. Soc., 31: 15-21. http://doi.acm.org/10.1145/504696.504699

5. Kahn, T., 1991. A new model of education: Designing virtual communities for creativity and learning. $\mathrm{http} / / / \mathrm{ww} w$. edutopia.org/designingvirtual-communities-creativity-and-learning

6. Lim, J.K.S. and E.M. Edirisinghe, 2007. Teaching computer science using SecondLife as a learning environment. In ICT: Providing choices for learners and learning. Proceedings of the Ascilite Singapore, pp: $1-4$.

http://www.ascilite.org.au/conferences/singapore07 /procs/lim.pdf

7. National Institutes of Health. http://www.nlm.nih.gov/pubs/checklist.pdf

8. Ritzema T. and B. Harris, 2008. The use of SecondLife for distance education. Comput. Sci. J. Comput. Sci. in Colleges, 23: 110-116. http://portal.acm.org/citation.cfm?id=1352403

9. SeniorNet. http://www.seniornet.org/jsnet/index.php?option=c om_frontpage\&Itemid $=1$

10. Teach and Learn. http://www.teachandlearn.ca/blog/2008/03/31/thevirtual-classroom-project/

11. Vanden, A., V.A. and V. Van Rompaey, 2006. Introducing human-centered research to game design: Designing game concepts for and with senior citizens. Proceeding of the CHI '06 Extended Abstracts on Human Factors in Computing Systems, Apr. 22-27, ACM Press, New York, USA., pp: 1469-1474. http://doi.acm.org/10.1145/1125451.1125721

12. Wikipedia. http://en.wikipedia.org/wiki/Second_Life 